Towards this objective, I would recommend the following rules:

(a) Questions about age, gender, race, nationality, place of birth, marital status and pre-professional education should not appear on application forms.

(b) No candidate who is not a member of the College may be shortlisted for a senior registrar or consultant appointment.

(c) If the only qualified candidates are nonwhite, the interviews should go ahead.

(d) Members of Advisory Appointments Committees should devise questions that would simply test a candidate's knowledge, skills and attitudes, and not refer to the candidate's ethnic or racial origin.

Having - in spite of my qualifications, experience and contributions to service provision and to education and training in psychiatry - had the personal experience of racial discrimination in my professional career in this country, I hope that our College will take the lead in encouraging non-racial thinking and in evolving a culture of genuine equality of opportunity.

IKECHUKWU O. AZUONYE, Forest Healthcare NHS Trust, Claybury Hospital, Manor Road, Woodford Bridge, Essex IG8 8BY

Sir: In 1987 Council established a Special Committee with the following terms of reference:

(a) to explore issues attending the training of psychiatrists and the practice of psychiatry in British multi-ethnic society

(b) to investigate the problems of discrimination against trainees, other doctors in psychiatry and patients on the grounds of race and to make recommendations.

The Special Committee, chaired by Professor Kenneth Rawnsley, presented its report to council in June 1989. Copies of this report are available from the College.

Twenty-four specific recommendations were made including the following "The College, perhaps through the Court of Electors, should ensure that regular monitoring takes place of the distribution by sex and ethnicity of new Fellows, Regional Advisers and their Deputies and examiners in the MCRPsych. Council accepted this recommendation but further agreed that there should be no discrimination by sex or ethnicity when members were being considered for membership of College committees, including the board of Examiners, for the Fellowship or for Distinction Awards".

The College obviously had information about the gender of its membership but no information on ethnicity. The College members were there- fore circulated with a letter and a form from the Registrar collecting ethnic information in September 1990 and it has recently been agreed that this information should be regularly collected from new Inceptors, Members and Fellows of the College. Throughout this exercise the methodology and the classifications used have been the same as those which are used by the Office of Population, Censuses and Surveys which was updated for the 1991 population census. Further letters were sent out in January 1993 with reminders in July 1993.

Council reaffirmed its wish to collect ethnic information on its Members in 1993 and a working group was set up under the Chairmanship of Professor J. Cox to monitor the implementation of the recommendations of the 1987 Special Committee. Further, the establishment of a transcultural psychiatry special interest group may be expected to have a particular interest in the success of the ethnic monitoring service.

Members may wish to know that out of 5643 members and fellows residing in the United Kingdom, 1423 did not return their questionnaires, 65 returned blank questionnaires and 14 of these were accompanied by letters of objection. Seven completed questionnaires were accompanied by letters expressing strong support for the College's initiative.

With regard to Dr Azuonye's four recommendations, we are pleased to be able to report that these are in fact already College policy. College assessors on Advisory Appointments Committees attend a training day in which issues of equal opportunity feature prominently, both in didactic presentation and in role play. The College does not approve the appointment of a psychiatrist without membership to senior registrar, let alone consultant appointments, and takes firm action when this occurs without approval.

Chris ThOMPSON, Registrar; and JOHN L. CoX, Dean, Royal College of Psychiatrists

\section{Shortage of beds}

Sir: As a psychiatric registrar working in the same region. I agree with Dr Foster (Psychiatric Bulletin, June 1994, 18, 371-372) that the shortage of acute beds is worsening. However, while this may pressurise juniors to avoid admissions, I do not share the sense of inevitability conveyed by her letter. This situation only arises when juniors allow wider managerial issues to cloud clinical judgement. Junior doctors are not in a position to deal with such issues unaided and attempts to do so may expose patients to increased risk while possibly exacerbating the underlying problem of insufficient beds. 